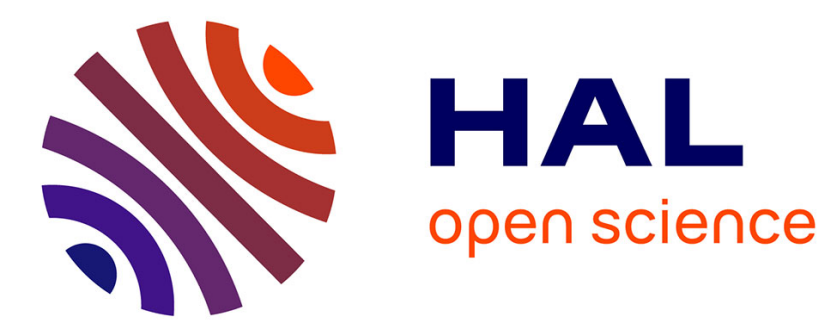

\title{
Multiscale approach of spin crossover materials - a concept mixing Russian dolls and domino effects
}

Philippe Guionneau, Mathieu Marchivie, Guillaume Chastanet

\section{To cite this version:}

Philippe Guionneau, Mathieu Marchivie, Guillaume Chastanet. Multiscale approach of spin crossover materials - a concept mixing Russian dolls and domino effects. Chemistry - A European Journal, 2021, 7 (5), pp.1483-1486. 10.1002/chem.202002699 . hal-02945195

\section{HAL Id: hal-02945195 \\ https://hal.science/hal-02945195}

Submitted on 9 Oct 2020

HAL is a multi-disciplinary open access archive for the deposit and dissemination of scientific research documents, whether they are published or not. The documents may come from teaching and research institutions in France or abroad, or from public or private research centers.
L'archive ouverte pluridisciplinaire $\mathbf{H A L}$, est destinée au dépôt et à la diffusion de documents scientifiques de niveau recherche, publiés ou non, émanant des établissements d'enseignement et de recherche français ou étrangers, des laboratoires publics ou privés. 


\title{
Multiscale approach of spin crossover materials - a concept mixing Russian dolls and domino effects
}

\author{
Philippe GUIONNEAU*, Mathieu MARCHIVIE, Guillaume CHASTANET
}

\author{
Pr Dr HdR Philippe GUIONNEAU, Dr Mathieu MARCHIVIE, Dr HdR Guillaume CHASTANET \\ CNRS, Univ. Bordeaux, Bordeaux INP, ICMCB, UMR 5026 \\ 87 av. Dr A. Schweitzer, F-33600 Pessac (France) \\ corresponding author: philippe.guionneau@icmcb.cnrs.fr
}

\begin{abstract}
The spin crossover (SCO) phenomenon corresponds to a modification that originates at the atomic scale. However, the simple consideration of the transformations that occur following the SCO at this scale or in its close vicinity does not allow anyone to truly understand, anticipate and thus take advantage of what happens at the scale of the material, and even less at the device one. As the fruit of years of work and experience on this phenomenon, we formalize here the concept of the multiscale understanding of SCO. Clearly, the deflagration generated by the initial impressive atomic modification on all the physical scales of the solid must be understood in terms of structure-properties relationships that fit together, like Russian dolls, and propagate according to a kind of domino effect. Each scale can both give different and independent consequences from those of the other scales but at the same time can influence those of a larger or smaller scale, the whole being imperatively to take into account. The concept appears well illustrated by the volume modification, always the same at the atomic level but drastically different and adaptable, in amplitude and sense, at any other physical scale. This approach results in a much wider range of potential applications than the atomic level alone initially suggests, including one serious path to shape memory materials.
\end{abstract}

Spin crossover (SCO) materials are often mentally associated with phenomena and potential applications that deal with magnetic bi-stability. This is mainly due to historical reasons that give a key role to the molecular magnetism scientific community, literally as the precursor community in highlighting, investigating and promoting this phenomenon [1]. Today, however, interest in this phenomenon goes far beyond this initial scientific community. Indeed, as much as the changes in magnetic and optical properties associated with this phenomenon are astounding and of exceptional richness, so many other aspects are now coming to the forefront, both fundamentally and in terms of practical applications [2]. For example, changes in the shape and size of materials, possibly in the form of crystals or composites, when undergoing SCO are of major interest because of their amplitude, diversity, controllability and the multiplicity of stimuli that can be used. The latter include thermo-, piezo- and photo-stimuli as well as any combination. Indeed, the change of mechanical properties in response to external stimuli in SCO crystals, including possible up to $10 \%$ volume reversible jumps [3, 4], can lead to consider them as a family by their own into the attractive world of stimuli-responsive materials aside for instance well known diarylethene based molecular crystals [5] or thermo-salient crystals [6, 7]. To date, actuators represent, indeed, one of the greatest opportunities for SCO solids [7, 8].

The SCO is a phenomenon that corresponds to a modification of the electronic configuration in some metal ions due to at least one external stimulus. It is therefore, intrinsically, an atomic-scale phenomenon. However, as developed below, all the physical scales of the SCO solid account to truly master the diversity of the corresponding physical properties. This leads us to state the concept of a multiscale approach. To some extent, this mutiscale concept is reminiscent from the concept of reaction cavity in condensed matter that deals with the effects of the environment of a chemical specie on the solid properties [9]. For example, for iron(II) ions that are the most studied ones and on which the discussion below will therefore focus, SCO implies an interchange between the high-spin (HS) and the low-spin (LS) configurations. In this case, the HS to LS modification involves a paramagnetic/diamagnetic transition, inducing most of the time a change of color, and a drastic decrease of the iron to surrounding-atoms distances $[4,10]$. Depending on the compound, however, the SCO can be reversible, or not, and, interestingly, at the scale of the sample can lead to an incredible diversity of physical behaviors providing a rich panel of properties, sometimes even antagonists from one sample to another. The reason is that, spreading from the metal ion, the SCO propagates to all other physical scales, each of them reacting differently and each of them may or may not, depending on the solid in question, act on the others. Indeed, all scales of the material from the coordination polyhedron to the macroscopic object reflect in different ways, each with its own characteristics, the initial perturbation of the electronic configuration corresponding to the SCO. All the physical properties of the sample, or even of the device, are thus influenced by what happens at all levels of the material. To date, though the SCO phenomenon is thoroughly investigated, all the links between the atomic scale modifications and its macroscopic consequences are far to be understood since, very often, new data provide unexpected or non-anticipated behaviors $[2,11]$. The causal chains are still to be understood in a global picture. One key point to achieve the latter is to envisage a multiscale view.

The most spectacular and obvious multi-scale causal chain to observe and describe is probably that of structural changes. Firstly, because crystallography's characterization tools are very advanced and allow the investigation of a chosen physical scale. For example, in radiation diffraction, information on coherent domains, physical scale of the $\mathrm{nm}$, can be obtained 
simultaneously on the same image (the same diffractogram) as that relating to the atomic environment of the metal ion $(\AA)$ or the parameters of the unit-cell (a few $\AA$ ). This is obtained via different characteristics that are very weakly correlated such as, respectively, the width, the intensities and the positions of the Bragg peaks. Secondly, structural changes in SCO materials, especially those based on $\mathrm{Fe}(\mathrm{II})$ compounds, appear sometimes so huge in molecular crystals that they might challenge the very concept of solid when their reversible nature is taken into account leading to the notion of fatigability. Thus, over the last three decades of studies, the accumulation of structural data has made it possible to evidence the pathway at the different scales of modifications related to SCO, in all its diversity (Figure 1). Among them, the volume change can be taken as the narrative thread explaining the complexity of what happens in a crystalline solid subject to SCO. In this regard, it is necessary to be sharp on the vocabulary, which was not always the case in the initial studies reported in the literature that could have been a source of confusion. In particular, the term "volume", which is widely used in publications discussing SCO materials, deserves to be clarified. The volume modification of the coordination polyhedron due to the SCO $\left(\Delta \mathrm{V}_{\text {poly }}\right)$ is the same whatever the compound and the material, it depends only on the type of metal ion and the atoms bonded to form the polyhedron [4]. For instance, for one iron(II) metal ion surrounded by six nitrogen atoms, the polyhedron volume modification at the SCO is always $\Delta \mathrm{V}_{\text {poly }}=$ 3.0(3) $\AA^{3}$ (from 13.0(3) $\AA^{3}$ in HS to 10.0(2) $\AA^{3}$ in LS). This corresponds to a decrease of $23 \%$ when going from HS to LS by cooling, applying pressure or reverse light irradiation and an increase of $30 \%$ when going from LS to HS by warming, negative pressure or light irradiation [10]. Note that for the sake of clarity we illustrate below values in the SCO sense from HS to LS. This spectacular volume change is then modulated at the scale of the molecule, which can reacts in very different ways including modifications of conformation and bond breaking for instance $[10,11,12]$. The volume variation on this scale appears extremely variable from one molecular complex to another but is very often between 0.5 and $5 \%$, approximately [13]. The volume variation of the molecule is therefore very small compared to the variation of the polyhedron. This systematically implies a rearrangement of the ligands around the metal to compensate for the expansion of the coordination sphere that, again, offers a large panel of behaviors. Such a diversity is fascinating, involving, for example, changes in conformation [10, 12a], ligand rotations [14] and even bond breaks [8b, 9b]. Although the increase in volume at the molecule scale is relatively moderate, the rearrangement of the ligands has a significant impact at the higher scale, which leads, in most cases, to a significant expansion of the crystal lattice. The upper scale, the crystal lattice, is then also affected, to a greater or lesser extent depending on the flexibility of the molecular rearrangement. Sometimes it generates first order phase transition, ultimately symmetry breaking, and/or large modifications such as molecular shifts or chains rotations and/or twinning [3, 7-16]. The result is that the volume variation of the unit-cell is never as high as the initial $-23 \%$ of the polyhedron from HS to LS. Instead, the variation of the unit-cell size, $\Delta \mathrm{V}_{\text {unit-cell, appears quite }}$ commonly in the range between -2 and $-5 \%[4,10]$ but can also, in rare cases, exceed $-10 \%$ [3]. Note that it may be also almost null and even, as very recently highlighted, be in the opposite sense as shown by the $\Delta \mathrm{V}_{\text {unit-cell }}$ of $+1.6 \%$ from $\mathrm{HS}$ to $\mathrm{LS}$ reported in an iron(II) molecular crystal in relation with a rotation of ligand at the SCO [14]. The consequences of this change of volume at the upper scales, notably the coherent-domain one and the sample itself, are less documented in the literature. The investigation of the coherent domain, i.e. the space that contains strictly a unique periodic atomic packing, appears quite recent in the SCO field. The reported results indicate already very interesting features and indubitably add a degree to the complexity of the multiscale response to SCO [17]. Some results tend to show that the amplitude could be very similar to the unitcell one $[3,17]$. This is however probably very dependent on the sample, notably on its nature (single-crystal, powder, nanoparticules). The macroscopic volume change of the sample itself is also a data poorly documented, though some attempts by optical microscopy have been reported [18]. Many compounds studied evidenced a structural fatigability upon cycling them, as a result of all these mechanical strains spreading on all the physical scale of the material. Crystals can sometimes explode but, in some cases a strong mechanical resilience [19] or a thermal healing process have been observed [17b], illustrating that a generality is not a totality. Incidentally, recalling that the change in volume can be reversible by applying a stimulus that may or may not be of the same nature, one can appreciate how SCO crystals are very good candidates for shape memory materials.

The above example of the volume change therefore illustrates the multiscale aspect of SCO but one can imagine how much more complicated it is in reality given the number of parameters to be taken into account and the number of events that can take place. Note that this global concept goes far beyond the notion of cooperativity used in the literature as a key aspect to describe the SCO features but that is commonly only related to intermolecular interactions. The real description of the cooperativity of the SCO shall undoubtedly use this concept of multiscale approach to establish the future theoretical models. To help conceptualize a complete view, Figure 1 attempts to list the structural information to which each physical scale gives access in order to have a fairly complete description of this phenomenon. Each scale tends to adapt its features to the initial effect of the change in the electronic coordination of the metal by accommodating the change generated at the lower physical scale. Finally, this interconnection of behaviour between different physical scales is quite common within a solid, especially molecular, but what makes it both rich and more specific in the case of SCO is the reciprocal nature of influences between scales. Indeed, if, as we have seen, information about change due to SCO spreads from the smallest to the largest scale, carrying with it its share of modifications, a structural feature at a given scale can also have an influence on smaller scales. For example, the fine description of the distortion of the cation polyhedron at the SCO that is easily accessible by variable temperature structural investigation [20] and is known to be crucial for the photo-induced physical properties [21], can be influenced by upper scales, even the crystal packing one. This is largely documented by the comparison of true polymorphs that, by definition, only differ from their crystal packing and can show very different polyhedron distortions at the SCO. Polymorphism that represents a great chance in the study of SCO materials are very often used to indeed highlight scale effects [22]. It could be argued that the causality between differences in distortions and crystal-packings is close to the chicken-and-egg problem, but 
other facts abound in the direction of the influence of the upper scales on the lower ones. For example, the particle size reduction by grinding involves significant modifications to smaller physical sizes resulting in the alteration of the SCO features [23] Even more impressively, the morphological characteristics of the macroscopic crystalline sample could decide the start of the SCO at the atomic scales [24].

The concept of multiscale in SCO can be imaged by a domino effect blended to a Russian dolls architecture. The domino effect is a chain reaction that occurs when a change causes an identical change in close proximity, which will cause another similar change, and so on. The domino effect refers to the spin conversion reaction chain from one metal site to another driven by the first ions that undergo a transition. The analogy of Russian dolls, can be used to account for all the physical scales. Indeed, the investigation of any one of them cannot give a complete picture and is insufficient to explain the modification of the physical properties of the sample in the SCO one view hiding the other one like one of the Russian doll hides the smaller ones. Note that the Russian dolls analogy gives only a partial picture because in reality each scale may influence the others. Therefore if this image of the multi-scale SCO concept is probably a matter of popularizing science, it also conveys for specialists the message that all events and characteristics related to each of the physical scales must be taken into account. This appears crucial not only for a fundamental understanding but also for any development of a reliable application using SCO.

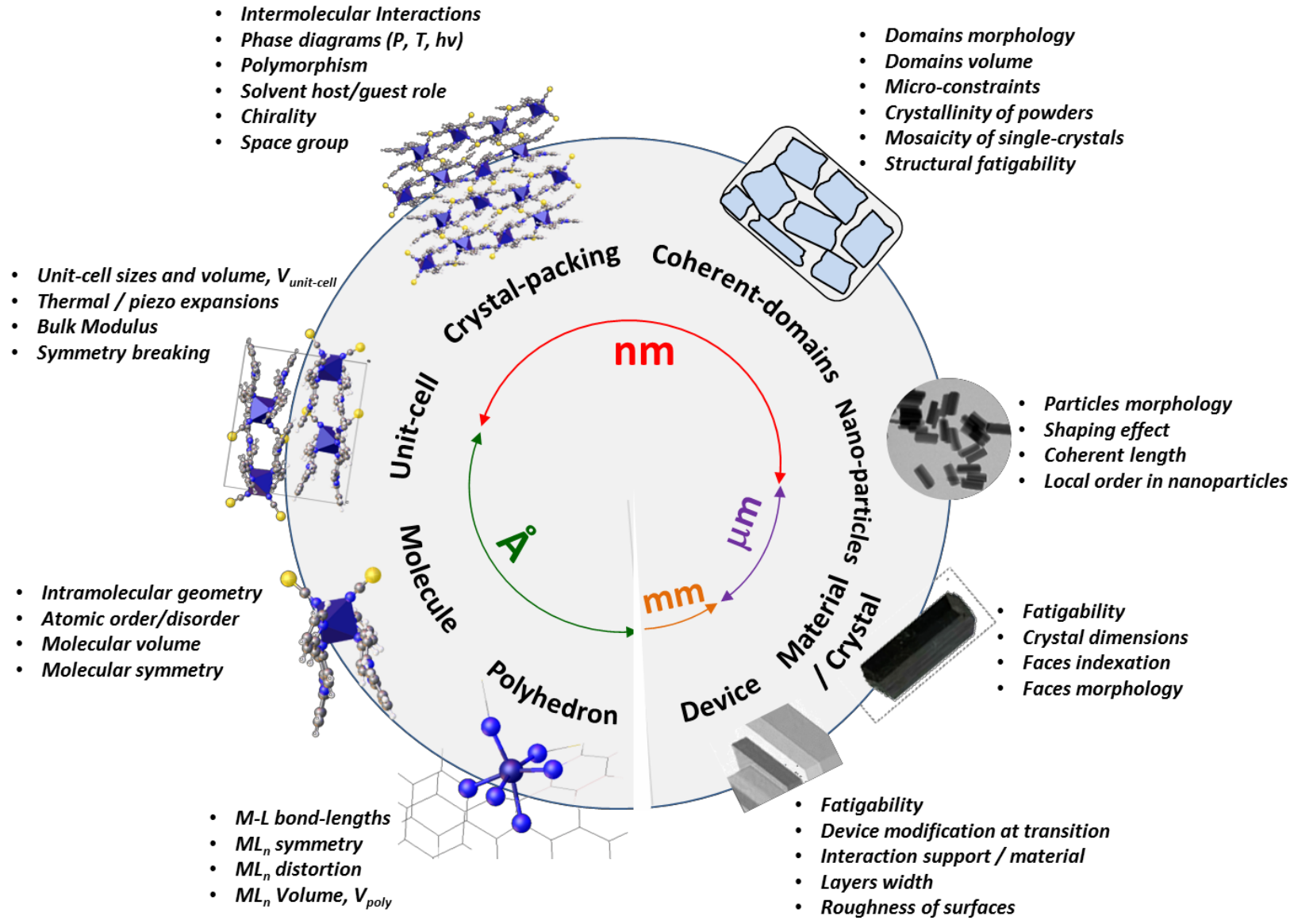

Figure 1. Conceptual view of all scales playing a crucial and complex role on the spin-crossover (SCO) process into a material. From the atomic ion and its polyhedron to the device, each scale reacts and provide significant changes, with or without links to others. The useful structural data that can be retrieved from each scale notably through crystallography analysis are emphasized here, which includes modifications due to SCO. The structure-property pattern is clearly reciprocal at each scale since structural properties depends on the SCO features but SCO features can also depend on concerned structural properties, the whole defining a Russian dolls domino effect.

Keywords: spin crossover $\cdot$ volume $\cdot$ physical scale $\bullet$ cooperativity $\cdot$ mechanism

[1] a) O. Kahn, Molecular Magnetism, VCH Publishers, New York, 1993; b) P. Gütlich, H.A. Goodwin (eds) Spin Crossover in Transition Metal Compounds I-III. Top. Curr. Chem., vols. 233 - 235. Springer, Berlin /
Heidelberg, Germany, 2004; c) M. A. Halcrow, Spin-Crossover Materials Properties and Applications, Wiley, Chichester, 2013;

[2] a) G. Molnár,bL. Salmon, W. Nicolazzi, F. Terki, A. Bousseksou J. Mater. Chem. C 2014, 2, 1360-1366; b) K. Boukheddaden, M.H. Ritti, G. Bouchez, M. Sy, M. M. Dîrtu, M. parlier, J. Linares, Y. Garcia, J. Phys. Chem. C 2018, 122, 14, 7597-7604; c) B.R. Mullaney, L. Goux- 
Capes, D.J. Price, G. Chastanet, J-F. Létard, C.J. Kepert, Nat. Commun. 2017, 8, 1053; d) K.S. Kumar, M. Studniarek, B. Heinrich, J. Arabski, G. Schmerber, M. Bowen, S; Boukari, E. Beaurepaire, J. Dreiser, M. Ruben, Adv. Mat. 2018, 30, 11, 1705416; e) M. Estrader, J.S. Uber, L.A. Barrios, J. Garcia, P. Lloyd-Williams, O. Roubeau, S.J. Teat, G. Aromi, Angew. Chem. Int. Ed. Engl. 2017, 56, 49, 1562215627 ; f) H. Li, H. Peng, Current Opinion in Colloid \& Interface Science 2018, 35, 9-16.

[3] A. Grosjean, P. Négrier, P. Bordet, C. Etrillard, D. Mondieig, S. Pechev, E. Lebraud, J.-F. Létard and P. Guionneau, Eur. J. Inorg. Chem. 2013, 796-802.

[4] P. Guionneau, Dalton Trans. 2014, 43, 382-393.

[5] A. Hirano, D. Kitagawa, S. Kobatake, CrystEngComm 2019, 21, 24952501.

[6] B.A. Zakharov, A.A. Michalchuk, C.A. Morrison, E.V. Boldyreva, (2018). Phys. Chem. Chem. Phys. 2018, 20(13), 8523-8532.

[7] P. Naumov, S. Chizhik, M.K. Panda, N.K. Nath, E. Boldyreva, Chem. Rev. 2015, 115, 12440-12490;

[8] a) M.D. Manrique-Juarez, S. Rat, L. Salmon, G. Molnar, C. M. Quintero, L. Nicu, H. J. Shepherd, A. Bousseksou, Coord. Chem. Rev. 2016, 308, 395-408; b) O. Sato, Nature Chem 2016, 8, 644-656; c) A. Worthy, A. Grosjean, M.C. Pfrunder, Y. Xu, C. Yan, G. Edwards, J.K. Clegg, J.C. McMurtrie, Nature Chem 2018, 10, 65-69.

[9] a) T. Luty, C.J. Eckhardt, J. Am. Chem. Soc. 1995, 117(9), 2441-2452; b) E.V. Boldyreva, Solid State lonics 1997, 101, 842-849.

[10] a) M. A. Halcrow, Chem. Soc. Rev. 2011, 40, 4119-4142; b) P. Guionneau, M. Marchivie, G. Bravic, J.-F. Létard, D. Chasseau, Top. Curr. Chem.2004, 234, 97-128; c) E. Collet, P. Guionneau, C. R. Chim. 2018, 21, 1133-1151.

[11] a) B. Weber, W. Bauer, J. Obel, Angew. Chem. Int. Ed. Engl. 2008, 47, 10098-10101 ; b) P. Guionneau, F. Le Gac, A. Kaiba, J. Sanchez-Costa, D. Chasseau and J.F. Létard, Chem. Commun. 2007, 3723-3725; c) H.J. Shepherd, T. Palamarciuc, P. Rosa, P. Guionneau, G. Molnar, J. F. Létard, A. Bousseksou, Angew. Chem. Int. Ed. 2012, 51, 3910-3914; d) M. Darawsheh, L.A. Barrios, O. Roubeau, S.J. Teat, G. Aromi, Chem. Eur. J. 2016, 25, 8635-8645.

[12] a) M.L. Boillot, S. Pillet, A. Tissot, E. Rivière, N. Claiser, C. Lecomte, Inorg. Chem. 2009, 48, 4729-476; b) D. Aguilà, P. Dechambenoit, M. Rouzières, C. Mathonière, R. Clérac, Chem. Commun 2017, 53, 1158811591.

[13] Molecular volumes have been obtained here from the Kitaigorodskii packing index [A.I. Kitajgorodskij, A.I. Molecular Crystals and Molecules, New-York, Academic Press, 1973] calculated by the VOID function of the PLATON software [A.L. Spek, Acta Cryst. 2009, D65, 148-155]. The packing index allows to calculate the volume occupied by the structure. Then, the volume of the molecule is estimated by dividing by $Z$. Results on different SCO molecules with different SCO features lead to variation between $0.5 \%$ and $1.5 \%$ in most of the case, and can reach up to $5.3 \%$ for 1D SCO coordination polymers based on triazole ligands.

[14] W. Guo, N. Daro, S. Pillet, M. Marchivie, E-E Bendeif, E. Tailleur, K. Chainok, D. Denux, G. Chastanet, P. Guionneau, Chem. -A Eur. J. 2020, in press

[15] a) M. Milek, F.W. Heinemann, M.M. Khusniyarov, Inorg. Chem. 2013, 52, 19, 11585-1159; b) A. Djemel, O. Stefanczyk, M. Marchivie, E. Trzop, E. Collet, C. Desplanches, R. Delimi \& G. Chastanet Chem. - A Eur. J. 2018, 24, 14760-14767.

[16] a) D. Chernyshov, M. Hostettler, K.W. Törnroos, H.B. Bürgi, Angew. Chemi. Int. 2003, 42(32), 3825-3830 ; b) K.W. Törnroos, M. Hostettler, D. Chernyshov, B. Vangdal, H.B. Bürgi, Chem.-A Eur. J. 2006, 12(24), 6207-6215.

[17] a) A. Grosjean, N. Daro, S. Pechev, L. Moulet, C. Etrillard, G. Chastanet, P. Guionneau, Eur. J. Inorg. Chem 2016, 1961-1966; b) A. Grosjean, N. Daro, S. Pechev, L., C. Etrillard, G. Chastanet, P. Guionneau Eur. J. Inorg. Chem. 2018, 429-434; c) S. Lakhloufi, E. Tailleur, W. Guo, F. Le Gac, M. Marchivie, M.-H Lemée-Cailleau, G. Chastanet, P. Guionneau, Crystals 2018, 8, 363.

[18] a) C. Chong, A. Slimani, F. Varret, K. Boukheddaden, E. Collet, J. C. Ameline, R. Bronisz \& A. Hauser Chem. Phys. Lett. 2011, 504, 29-33; b) H. Fourati, E. Milin, A. Slimani, G. Chastanet, Y. Abid, S. Triki \& K. Boukheddaden Phys. Chem. Chem. Phys. 2018, 20, 10142-10154; c) A. Slimani, F. Varret, K. Boukheddaden, C. Chong, H. Mishra, J. Haasnoot \& S. Pillet Phys. Rev. B - Condens. Matter Mater. Phys. 2011, 84, 1-8.

[19] N. Pittala, F. Thétiot, S. Triki, K. Boukheddaden, G. Chastanet, M. Marchivie, Chem. Mater. 2017, 29, 490-494.

[20] S. Lakhloufi, M.H. Lemee-Cailleau, G. Chastanet, P. Rosa, N. Daro, P. Guionneau, Phys. Chem. Chem. Phys. 2016, 18, 28307-28315.

[21] M. Marchivie, P. Guionneau, J.-F. Létard, D. Chasseau, Acta Cryst. 2005, B61 (2005) 25-28.

[22] a) J. Tao, R.-J. Wei, R.-B. Huang \& L.-S. Zheng Chem. Soc. Rev. 2012, 41, 703-737; b) W. Phonsri, C.G. Davies, G. N. L. Jameson, B. Moubaraki, K.S. Murray, Chemistry - A Eur. J. 2016, 22(4), 1322-1333; c) G.S. Matouzenko, E. Jeanneau, A.Y. Verata, A. Bousseksou, Dalton Trans. 2011, 40, 9608-9618; d) A.E. Thorarinsdottir, A.I. Gaudette, T.D. Harris, Chem. Sci. 2017, 8, 2448-2456; e) T.M. Ross, B. Moubaraki, S.M. Neville, S.R. Batten, K.S. Murray, Dalton Trans. 2012, 41, 15121523; f) A. Arroyave, A. Lennartson, A. Dragulescu-Andrasi,K.S. Pedersen, S. Piligkos, S.A. Stoian,S.M. Greer, C. Pak, O. Hietsoi, H. Phan, S. Hill, C.J. McKenzie, M. Shatruk, Inorg. Chem. 2016, 55, 5904-5913.

[23] a) D. Nieto-Castro, F.A. Garcés-Pindeda, A. moneo-Corcuera, B. PatoDoldan, F. Gispert-Guirado, J. Benet-Buchholz, J.R. Galan-Mascaros, Inorg. Chem. 2020, 59, 7953-7959. b) M.S. Haddad, W.D. Federer, M.W. Lynch, D.N. Hendrickson, Inorg. Chem. 1981, 20, 131-139.

[24] K. Boukheddaden, M. Sy, Current Inorganic Chemistry 2016, 6, 40-48. 


\section{Entry for the Table of Contents}

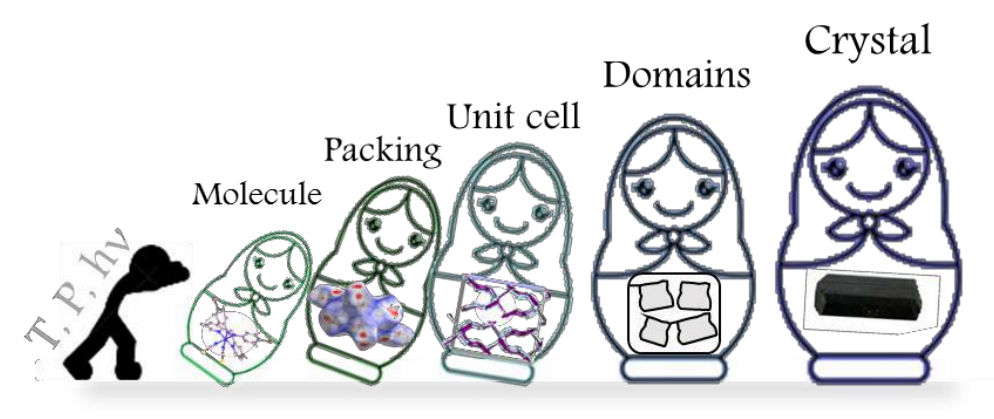

Although of purely atomic origin, the Spin CrossOver spreads like a cascade of dominoes to all the dimensions of a material which fit together like Russian dolls with not only extremely different effects in nature and in amplitude but also with a mutual inter dependence. The multi-scale description is then the only way to understand the whole impact of a SCO on a material, incidentally showing the power of the crystallography approach. This concept could be extended to many other molecular phenomena. 